\title{
Effect of rapeseed oil aromatisation with marjoram on the content of volatile fraction and antioxidant properties
}

\author{
Radosław Kowalski ${ }^{1}$ (D) Grażyna Kowalska ${ }^{2} \cdot$ Urszula Pankiewicz $^{1}$ • \\ Marzena Włodarczyk-Stasiak ${ }^{1} \cdot$ Monika Sujka $^{1} \cdot$ Artur Mazurek $^{1}$
}

Revised: 26 July 2019/Accepted: 4 November 2019/Published online: 9 November 2019

(C) The Author(s) 2019

\begin{abstract}
The aim of the paper was to study how the process of aromatisation with marjoram affected the composition of volatile fraction and antioxidant properties of rapeseed oil. Different methods of aromatisation were used: direct addition of marjoram essential oil, classical macerations of marjoram herb, and maceration assisted with ultrasound or microwave. The dominant aromatic component in the volatile fraction was $\gamma$-terpinene with concentration in the range from $3.15 \mu \mathrm{g} / \mathrm{mL}$ (microwave assisted maceration) to $8.82 \mu \mathrm{g} / \mathrm{mL}$ (classic maceration with shaking). The content of this compound in the mixture of rapeseed oil with essential oil was $152.09 \mu \mathrm{g} / \mathrm{mL}$. The sample aromatized by the direct addition of essential oil contained the highest amount of volatile substances but simultaneously it had the lowest antioxidant activity.
\end{abstract}

Keywords Aromatisation - Rapeseed oil - Marjoram essential oil $\cdot$ Sonication $\cdot$ Microwave

\section{Introduction}

Aromatisation is the enrichment of products in flavour and aromatic compounds-comparatively strong-smelling organic substances with characteristic, mostly pleasant

Radosław Kowalski

radoslaw.kowalski@up.lublin.pl

1 Department of Analysis and Evaluation of Food Quality, University of Life Sciences in Lublin, 8 Skromna Street, 20-704 Lublin, Poland

2 Department of Tourism and Recreation, University of Life Sciences in Lublin, 15 Akademicka Street, 20-950 Lublin, Poland odours. Flavours are chemical substances sensed by cells of the olfactory epithelium and, to a lesser degree, by gustatory buds on the tongue (Bauer et al. 1990). The sense of smell is the most important in the sensing and perception of food aroma, and thus plays a great role in the sensory assessment of a product and consequently in the evaluation of its quality. It is a sense with high and versatile sensitivity, and therefore the consumer places it first among the traits responsible for the quality of a food product. The contemporary science on human nutrition presents the view that flavours should be treated as fundamental and significant components of food products (Tournier et al. 2007). Natural flavours, i.e. essential oils, find the most extensive application and are used among others as agents for food preservation. This is due to consumers' concerns regarding the safety and the negative effects of the use of synthetic food additives (Bruni et al. 2004).

Essential oils of plants are soluble in fats and there can be extracted with their help. Suitably prepared herbal material is put directly into fat or placed in flax bags immersed in fat. The process can be accelerated by means of slow stirring. The absorbents used include vegetable oil, olive oil, a mix of tallow and lard. The time of maceration is selected experimentally. After the extraction the raw material is removed and replaced with a fresh batch, repeating the process of extraction several times. Extracted material is separated through filtering or centrifuging, and residues of oil are extracted using a press. Aromatic oils obtained in this manner are called pomades or flavoured oils (Assami et al. 2016).

Essential oils are characterised by a broad spectrum of biological activity, including antimicrobial activity, and display a positive effect in combinations with synthetic food preservatives, allowing a reduction of the concentration of synthetic compounds applied. Such a role is played 
not only by isolated essential oils, but also by herbs and spices that contain those natural components and are used in e.g. canned food and pickles. Some foods and dishes are inseparably related with characteristic spices (Brud 2000). The addition of spices enables to increase the range of products by diversifying their taste and smell characteristics.

Herbs as spice are an important source of antioxidants, and apart from essential oils, they contain also other components (phenolic compounds, saponins, carotenoids) that inhibit the oxidation of lipids (Turek and Stintzing 2013). The addition of spices to food has an extremely long history and has been related with pleasure, valued by the hedonists as far back as the ancient times (Srinivasan 2005). The beginnings of the use of spices go back to the times when it was discovered that characteristic components occurring in natural products (aromas) can be easily obtained. Methods allowing to isolate those substances through extraction with olive oil or distillation have survived from the since ancient times till now. However, the original function of most spices was not to impart taste and flavour but primarily to conserve food (Brud 2000). Herbal spices are used as bactericidal and fungicidal agents for the control of correct run of lactic fermentation e.g. in the process of cucumber pickling.

Aromatised oils are a spice product in the kitchen that has been known for ages. Depending on the kind or aroma, aromatised oils can be added to meat dishes, salads, soups, sauces, and also to confectionery products (Ayadi et al. 2009). An alternative application of aromatised oils can be diet supplementation, where such products can be a source of health-promoting components for the organism. In addition, aromatised oils can be used in cosmetics. Aromatized oils can be obtained by classical maceration or with the use of ultrasound- or microwave-assisted methods. Previously published data indicate that the use of the latter methods can significantly accelerate the obtainment of the end product (Paduano et al. 2014).

The fact that aromatised oils are obtained through various physical processes was the impulse for undertaking a study in this area. Therefore the objective of this study was to estimate the effect of aromatisation of rapeseed oil with marjoram Origanum majorana on the content of volatile substances and to analyse the antioxidant properties of the aromatised oils obtained. The presented work is a continuation of research on fat aromatization with various raw plant materials (Kowalski et al. 2018).

\section{Materials and methods}

The experimental part was developed according to the procedure previously described (Kowalski et al. 2018).

\section{Experimental material}

The research material was constituted of the following: marjoram herb acquired from plant material from the herbal company Herbost (Kębłów, n. Piaski); rapeseed oil Kujawski (from so-called first cold pressing), ZT Kruszwica S.A. batch No. 15:33k.

\section{Essential oil distillation}

Hydrodistillation process (180 min) of marjoram essential oil was performed using a Deryng-type apparatus (Kowalski et al. 2018). The essential oil was collected in a vial and stored at below $-25{ }^{\circ} \mathrm{C}$ in the dark until tested and analysed. The distillation was performed in triplicate.

\section{Preparation of samples: aromatisation of oil}

\section{Classical macerations}

Marjoram flavored rapeseed oils were prepared by maceration of the herb of marjoram with $10 \%$ concentration $(w / v)$. Two samples of rapeseed oil $(100 \mathrm{~mL})$ were transferred to glass bottles. Next the dried herb of marjoram (10 g) was added to each bottles (in 3 replicates) and maceration was conducted: samples were taken at $60 \mathrm{~min}$ (samples A) and 300 min of maceration (samples B) with shaking $\left(25^{\circ} \mathrm{C}\right)$.

\section{Ultrasound-assisted macerations}

The samples of flavoured rapeseed oil were prepared similarly to classical maceration. Next the samples were subjected at $60 \mathrm{~min}$ (samples C) and $300 \mathrm{~min}$ of maceration (samples D) with sonication (ultrasound bath Sonic-6, Polsonic, Poland; ultrasound power, $240 \mathrm{~W}$; frequency, $40 \mathrm{kHz}, 25^{\circ} \mathrm{C}$ (the maceration in one continuous cycle).

\section{Microwave-assisted macerations}

The samples of flavoured rapeseed oil were prepared similarly to classical maceration and subjected to microwave treatment (samples E) for $60 \mathrm{~min}$ (MARS 5, CEM Corporation, Matthews, NC, USA; frequency, $2450 \mathrm{MHz}$, $\left.40{ }^{\circ} \mathrm{C}\right)$.

\section{Mixture of rapeseed oil with marjoram essential oil}

In addition mixture of rapeseed oil with marjoram essential oil was prepared (samples F)_rapeseed oil $100 \mathrm{~mL} /$ essential oil $120 \mu \mathrm{L}$ (obtained from herb of marjoram in an amount equivalent to the content for $10 \mathrm{~g}$ of raw herbal material). 
The macerates obtained (after filtering) and the mixture of rapeseed oil with marjoram essential oil were used directly for chromatographic analysis for the content of aromatic volatile substances. For that purpose, portions of $5 \mathrm{~mL}$ of the oil solutions were taken into a vial, adding 10 $\mu \mathrm{L}$ of a mixture of internal standards (dodecane, nonadecane). The codes of individual samples are explained in the description of Table 3 .

\section{Determination of fatty acids}

The rapeseed oil samples were prepared in accordance to previously described procedures by Kowalski (2007). Fatty acids from studied oil were converted to the corresponding fatty acid methyl esters (FAMEs) according to the literature (Kowalski 2009).

The GC-FID analyses of FAMEs were carried out on a GC Varian 450 system (Varian, USA) equipped with the Select $^{\mathrm{TM}}$ Biodiesel for FAME capillary column (30 $\mathrm{m} \times 0.32 \mathrm{~mm} \times 0.25 \mu \mathrm{m}$ film thickness), carrier gas $\mathrm{He} 28 \mathrm{~mL} / \mathrm{min}$, injector was set to $250{ }^{\circ} \mathrm{C}$. and the detector to $300{ }^{\circ} \mathrm{C}$; split ratio $1: 100$; injection volume $5 \mu \mathrm{L}$. GC oven temperature was programmed from $200{ }^{\circ} \mathrm{C}$ for $10 \mathrm{~min}$, then incremented by $3{ }^{\circ} \mathrm{C} / \mathrm{min}$ to $240{ }^{\circ} \mathrm{C}, 240{ }^{\circ} \mathrm{C}$ for $5 \mathrm{~min}$.

The percentage of fatty acids was presented assuming that the sum of peak areas for all identified constituents is $100 \%$ (method of internal normalisation).

\section{Determination of essential oil chemical composition}

\section{Gas chromatography operating conditions}

The GC analyses was performed in triplicate according to procedures described previously (Kowalski et al. 2015).

The GC-MS analyses were performed on a Varian 4000 GC-MS/MS system (Varian, USA), using the VF-5 ms silica capillary column $(30 \mathrm{~m} \times 0.25 \mathrm{~mm} ; 0.25 \mu \mathrm{m}$ film thickness), with $\mathrm{He}$ as the carrier gas at the flowrate of $0.5 \mathrm{~mL} / \mathrm{min}$. GC oven temperature was linearly programmed from 50 to $250{ }^{\circ} \mathrm{C}$ at the rate of $4{ }^{\circ} \mathrm{C} / \mathrm{min}$ and kept at $250{ }^{\circ} \mathrm{C}$ for $10 \mathrm{~min}$. The injector was set to $250{ }^{\circ} \mathrm{C}$ and the detector to $200{ }^{\circ} \mathrm{C}$, split ratio 1:50; injection volume $5 \mu \mathrm{L}$. Electron ionization mass spectra were acquired in scan mode in the $\mathrm{m} / \mathrm{z}$ range 40 to 870 ; EI mode, with ionization voltage $70 \mathrm{eV}$.

The GC-FID analyses were carried out on a GC Varian 3800 system (Varian, USA) equipped with the DB-5 fused silica capillary column $(30 \mathrm{~m} \times 0.25 \mathrm{~mm} \times 0.25 \mu \mathrm{m}$ film thickness), carrier gas $\mathrm{He} 0.5 \mathrm{~mL} / \mathrm{min}$, injector and detector FID temperatures $260{ }^{\circ} \mathrm{C}$; split ratio 1:100; injection volume $5 \mu \mathrm{L}$. The $\mathrm{GC}$ program was the same as those used for GC-MS analysis.

\section{Headspace-gas chromatography operating conditions}

The volatile fraction of the essential oils and the fat macerates (flavoured oils) were determined by the headspacegas chromatography method. The headspace sampler was a pressure-loop HT3 model (Teledyne Tekmar, USA). The HS parameters used were: GC cycle time $71.00 \mathrm{~min}$, valve oven temperature $200{ }^{\circ} \mathrm{C}$, transfer line temperature $200{ }^{\circ} \mathrm{C}$, platen/sample temperature $150{ }^{\circ} \mathrm{C}$, sample temperature equilibration time $10.00 \mathrm{~min}$, mixing time $1.00 \mathrm{~min}$, mixer stabilize time $0.50 \mathrm{~min}$, vial pressure $68.9 \mathrm{kPa}$, pressurization time $2 \mathrm{~min}$, pressure equilibration time $0.2 \mathrm{~min}$, loop fill pressure $34.5 \mathrm{kPa}$, loop fill time 2 min and inject time $1 \mathrm{~min}$. The loop volume used on the HT3 (injection volume into the GC) was $0.25 \mathrm{~mL}$. The GC-MS analyses were performed on a Varian $450 \mathrm{GC}$ with the type triple qadrupol Varian 320-MS (Varian, USA), using the VF$5 \mathrm{~ms}$ silica capillary column $(30 \mathrm{~m} \times 0.25 \mathrm{~mm} ; 0.25 \mu \mathrm{m}$ film thickness), with $\mathrm{He}$ as the carrier gas at the flowrate of $0.5 \mathrm{~mL} / \mathrm{min}$. GC oven temperature was linearly programmed from 50 to $250{ }^{\circ} \mathrm{C}$ at the rate of $4{ }^{\circ} \mathrm{C} / \mathrm{min}$ and kept at $250{ }^{\circ} \mathrm{C}$ for $10 \mathrm{~min}$. The injector was set to $250{ }^{\circ} \mathrm{C}$ and the detector to $200{ }^{\circ} \mathrm{C}$, split ratio 1:50; injection volume $5 \mu \mathrm{L}$. Electron ionization mass spectra were acquired in scan mode in the $\mathrm{m} / \mathrm{z}$ range 40 to 1000 with $0.8 \mathrm{~s} / \mathrm{scan}$; EI mode, with ionization voltage $70 \mathrm{eV}$.

\section{Qualitative and quantitative analysis}

The components were identified by comparing linear retention indices (RI), their retention times (RT) and mass spectra with those obtained from the authentic samples and/or the MS library (Kowalski and Wawrzykowski 2009). The quantitative analysis (internal standard addition method-alkanes C12 and C19) were performed according to previously described procedures (Kowalski and Wawrzykowski 2009). In addition, the relative percentages of the separated compounds were calculated from integration of the peak areas in the GC chromatograms.

\section{Preparation of samples: estimation of antioxidant properties}

The antioxidant properties was assessed using the DPPH. method, as described by Sánchez-Moreno et al. (1998). An aliquot $100 \mu \mathrm{L}$ of the aromatised oils was added to $2 \mathrm{~mL}$ of methanol in a vials and solutions were stirred. Portions of $0.5 \mathrm{~mL}$ of the solutions were taken and $3.5 \mathrm{~mL}$ of DPPH solution was to added to each of them (conc. $0.025 \mathrm{mg} / \mathrm{mL}$, with specific absorbance at $515 \mathrm{~nm})$. Absorbance was measured after $30 \mathrm{~min}$ at $515 \mathrm{~nm}$ (spectrophotometer UV Carry 100, Varian). The antioxidant activity of the 
macerates was expressed as a percentage of quenched DPPH radical after incubation with analysed sample for $30 \mathrm{~min}$. in relation to the initial absorbance of DPPH solution.

The antiradical activity of the macerates was expressed in Trolox equivalents $[\mathrm{mg} / 100 \mathrm{~mL}]$ calculated by creating a standard curve of Trolox standards versus their absorbance.

\section{Statistical analysis}

Data were analysed using one way ANOVA followed by Duncan's test using the SAS statistical system (SAS Version 9.1, SAS Inst., Cary, N.C., U.S.A.). The significance of all tests was set at $p \leq 0.05$.

\section{Results and discussion}

\section{The content of essential oil and fatty acids composition}

The content of essential oil in herb of marjoram was $1.19 \%$ v/w. Compilation of the results of chromatographic analysis of fatty acids of rapeseed oil Kujawski is given in Table 1.

In chromatographic analysis 14 fatty acids were identified (Fig. 1). The dominant fatty acid in the analysed fraction was oleic acid with a content of above $60 \%$ $(60.28 \pm 0.39)$. Among the other main fatty acids of the rapeseed oil we should include linoleic acid, with content of ca. $20 \%$, and $\alpha$-linolenic acid with content of ca. $9 \%$. The results obtained are in conformance with literature data: $\quad \mathrm{C}_{18: 1}-63.57 \%, \quad \mathrm{C}_{18: 2}-17.45 \%, \quad \mathrm{C}_{18: 3}-9.34 \%$, $\mathrm{C}_{16: 0}-4.49 \%$ (Sigier et al. 2005). The composition of fatty acids is characteristic for cold-pressed low-erucic rapeseed oil. Rapeseed oil sonication for $300 \mathrm{~min}$. did not have any significant effect on the composition of fatty acids. Application of other physical factors (temperature, microwaves) had no effect on the fatty acid profile of the rapeseed oil.

\section{The essential oil chemical composition}

Table 1 present the results of GC chromatography analyses of marjoram oil. Essential oil obtained from marjoram through distillation displays traits intermediate between the terpineol chemotype (high content of terpinen-4-ol and the accompanying $\gamma$-terpinene, $\alpha$-terpinene and $\alpha$-terpineol) and the sabinol chemotype, with predominant occurrence of cis-sabinene hydrate and trans-sabinene hydrate and sabinene (Lis et al. 2007).

Chromatographic analysis of marjoram oil revealed the presence of 56 identified compounds (Table 1). The highest concentrations in the analysed essential oil were characteristic of trans-sabinene hydrate- $197.16 \mathrm{mg} / \mathrm{mL}$ (ca. 22\%) and terpinen-4-ol $(157.88 \mathrm{mg} / \mathrm{mL}, 17.61 \%)$. Components with significant concentrations in the volatile fraction included also $\gamma$-terpinene $(92.24 \mathrm{mg} / \mathrm{mL}, 10.29 \%)$, $\alpha$-terpinene $(59.26 \mathrm{mg} / \mathrm{mL}, 6.61 \%), \alpha$-terpineol $(52.46 \mathrm{mg} /$ $\mathrm{mL}, 5.85 \%)$, sabinene $(49.39 \mathrm{mg} / \mathrm{mL}, 5.51 \%)$ and cissabinene hydrate $(48.36 \mathrm{mg} / \mathrm{mL}, 5.39 \%)$.

\section{The content of volatile substances in the aromatised oils}

Table 2 present the results of GC analysis of the volatile fraction in rapeseed oil aromatised with herb of marjoram Origanum majorana. Chromatographic analysis of aromatised oils obtained experimentally (maceration) revealed the presence of 17 identified volatile components from the essential oil, while for the system prepared through direct addition of essential oil to rapeseed oil 21 substances were identified (Table 2, Fig. 2). The dominant aromatic component was $\gamma$-terpinene with concentration varied within the range from $3.15 \mu \mathrm{g} / \mathrm{mL}$ in macerate $\mathrm{E}$ (microwaves, $60 \mathrm{~min}, 40^{\circ} \mathrm{C}$ ) to $8.82 \mu \mathrm{g} / \mathrm{mL}$ in macerate $\mathrm{B}$ (classic maceration with shaking, $300 \mathrm{~min}, 25^{\circ} \mathrm{C}$ ), while in variant F (mixture of oil with essential oil) the content of $\gamma$-terpinene was $152.09 \mu \mathrm{g} / \mathrm{mL}$. Terpinen-4-ol constituted the highest concentration in variant $\mathrm{F}$ (mixture of oil with essential oil), with a level of $205.75 \mu \mathrm{g} / \mathrm{mL}$, while the level of that component in the macerates was notably lower: from 1.29 to $3.73 \mu \mathrm{g} / \mathrm{mL}$. Moreover, the main aromatic components of the macerates occurred in the individual variants at the following levels of concentration: $\alpha$-terpinene-from 1.89 to $5.13 \mu \mathrm{g} / \mathrm{mL}$ (for comparison, in oil $\mathrm{F}-88.05 \mu \mathrm{g} / \mathrm{mL}$ ), sabinene-from 1.47 to $4.86 \mu \mathrm{g} / \mathrm{mL}$ (in oil $\mathrm{F}-71.74 \mu \mathrm{g} / \mathrm{mL}$ ), and terpinolene-from 0.79 to $2.12 \mu \mathrm{g} / \mathrm{mL}$ (in oil F-35.76 $\mu \mathrm{g} / \mathrm{mL}$ ). In addition, the main aromatising components included also $\beta$-phellandrene and limonene. Statistical analysis of the results revealed that there were no significant quantitative differences for the main aromatised components of macerates obtained in different ways. Significant quantitative differences were found between macerates and oil aromatised through direct addition of essential oil.

The total concentration of substances in the sample prepared through direct addition of essential oil to rapeseed oil was $772.78 \mu \mathrm{g} / \mathrm{mL}$. Considerably lower concentration of volatile substances was observed in the macerates, which may result from the lower efficiency in extraction of volatile components using rapeseed oil compared to the yield of the distillation process. Aromatised oil obtained by shaking the raw material in oil- "B “, $300 \mathrm{~min}$. at $25^{\circ} \mathrm{C}-$ contained a total of $35.79 \mu \mathrm{g} / \mathrm{mL}$ of volatile components, while aromatised oil obtained with the use of sonication- 
Table 1 Chemical composition of individual components in marjoram essential oil

\begin{tabular}{|c|c|c|c|c|c|}
\hline \multirow[t]{3}{*}{ Compound } & \multirow[t]{3}{*}{ RI } & \multicolumn{4}{|l|}{ Concentration } \\
\hline & & \multicolumn{2}{|l|}{ A } & \multirow{2}{*}{$\begin{array}{l}\mathrm{B} \\
\%\end{array}$} & \multirow{2}{*}{$\begin{array}{l}\mathrm{C} \\
\%\end{array}$} \\
\hline & & $\mathrm{mg} / \mathrm{mL}$ & $\%$ & & \\
\hline$\alpha$-Thujene & 932 & $9.13 \pm 0.25$ & 1.02 & 1.13 & 0.53 \\
\hline$\alpha$-Pinene & 939 & $6.08 \pm 0.20$ & 0.68 & 0.64 & 0.25 \\
\hline Camphene & 955 & $0.20 \pm 0.01$ & 0.02 & tr. & 0.01 \\
\hline Sabinene & 976 & $49.39 \pm 1.78$ & 5.51 & 5.79 & 3.06 \\
\hline$\beta$-Pinene & 982 & $3.11 \pm 0.05$ & 0.35 & 0.11 & 0.23 \\
\hline Myrcene & 992 & $11.82 \pm 0.49$ & 1.32 & 1.68 & 0.89 \\
\hline$\alpha$-Phellandrene & 1006 & $1.86 \pm 0.04$ & 0.21 & 0.49 & 0.26 \\
\hline$\rho$-Menth-1(7),8-diene & 1007 & $0.36 \pm 0.01$ & 0.04 & tr. & 0.02 \\
\hline$\alpha$-Terpinene & 1018 & $59.26 \pm 2.39$ & 6.61 & 6.69 & 4.03 \\
\hline$\rho$-Cymene & 1025 & $9.44 \pm 0.06$ & 1.05 & 1.02 & 0.69 \\
\hline Limonene & 1029 & $12.65 \pm 0.34$ & 1.41 & 1.70 & 0.83 \\
\hline$\beta$-Phellandrene & 1030 & $17.07 \pm 1.12$ & 1.90 & 1.73 & 1.59 \\
\hline Z- $\beta$-Ocimene & 1037 & $0.60 \pm 0.18$ & 0.07 & tr. & 0.05 \\
\hline E- $\beta$-Ocimene & 1049 & $0.75 \pm 0.16$ & 0.08 & tr. & 0.13 \\
\hline$\gamma$-Terpinene & 1059 & $92.24 \pm 3.34$ & 10.29 & 10.80 & 8.22 \\
\hline cis-Sabinene hydrate & 1070 & $48.36 \pm 1.14$ & 5.39 & 5.10 & 4.55 \\
\hline Terpinolene & 1090 & $22.06 \pm 0.64$ & 2.46 & 2.46 & 1.69 \\
\hline Linalool & 1099 & $20.52 \pm 1.98$ & 2.29 & 2.37 & 2.73 \\
\hline trans-Sabinene hydrate & 1102 & $197.16 \pm 5.32$ & 21.99 & 26.40 & 30.16 \\
\hline cis- $\rho$-Menth-2-en-1-ol & 1123 & $15.82 \pm 0.12$ & 1.76 & 1.25 & 1.27 \\
\hline trans- $\rho$-Menth-2-en-1-ol & 1141 & $8.55 \pm 0.10$ & 0.95 & 0.76 & 0.70 \\
\hline Camphor & 1145 & $0.06 \pm 0.10$ & 0.01 & tr. & tr. \\
\hline Menthone & 1162 & $0.77 \pm 0.04$ & 0.09 & tr. & 0.07 \\
\hline Pinocarvacrol & 1169 & $0.38 \pm 0.14$ & 0.04 & tr. & tr. \\
\hline iso-Menthone & 1163 & $0.073 \pm 0.00$ & 0.01 & tr. & tr. \\
\hline Borneol & 1170 & $0.53 \pm 0.12$ & 0.06 & tr. & 0.04 \\
\hline Terpinen-4-ol & 1179 & $157.88 \pm 5.37$ & 17.61 & 20.14 & 27.65 \\
\hline$\alpha$-Terpineol & 1191 & $52.46 \pm 1.82$ & 5.85 & 2.75 & 5.53 \\
\hline cis-Dihydro carvone & 1196 & $0.37 \pm 0.09$ & 0.04 & tr. & tr. \\
\hline cis-Piperitol & 1201 & $2.94 \pm 0.43$ & 0.33 & 0.12 & 0.26 \\
\hline Nerol & 1232 & tr. & $\operatorname{tr}$. & tr. & 0.11 \\
\hline trans-Sabinene hydrate acetate & 1258 & $4.46 \pm 0.56$ & 0.50 & 0.30 & tr. \\
\hline Linalool acetate & 1259 & $25.04 \pm 2.03$ & 2.79 & 1.52 & 1.74 \\
\hline Bornyl acetate & 1290 & $0.46 \pm 0.14$ & 0.05 & 0.07 & 0.02 \\
\hline Thymol & 1294 & $0.94 \pm 0.76$ & 0.10 & 0.06 & 0.12 \\
\hline Menthyl acetate & 1300 & $0.24 \pm 0.16$ & 0.03 & tr. & tr. \\
\hline Carvacrol & 1304 & $1.15 \pm 0.37$ & 0.13 & 0.09 & 0.11 \\
\hline Terpinen-4-ol acetate & 1305 & $5.99 \pm 1.54$ & 0.67 & 0.44 & 0.33 \\
\hline$\delta$-Elemene & 1341 & $0.41 \pm 0.04$ & 0.05 & 0.05 & tr. \\
\hline$\alpha$-Terpinyl acetate & 1351 & $0.13 \pm 0.01$ & 0.01 & tr. & 0.01 \\
\hline Neryl acetate & 1364 & $0.66 \pm 0.31$ & 0.07 & tr. & 0.11 \\
\hline Geranyl acetate & 1385 & $1.40 \pm 0.59$ & 0.16 & tr. & 0.22 \\
\hline E-Caryophyllene & 1422 & $27.62 \pm 1.33$ & 3.08 & 2.32 & 1.14 \\
\hline Aromadendrene & 1444 & $0.53 \pm 0.05$ & 0.06 & 0.05 & tr. \\
\hline$\alpha$-Humulene & 1458 & $1.30 \pm 0.11$ & 0.15 & 0.09 & 0.04 \\
\hline allo-Alomadendrene & 1463 & $0.12 \pm 0.00$ & 0.01 & $\operatorname{tr}$ & tr. \\
\hline Viridiflorene & 1501 & $0.54 \pm 0.05$ & 0.06 & tr. & tr. \\
\hline
\end{tabular}


Table 1 continued

\begin{tabular}{llllll}
\hline Compound & RI & \multicolumn{2}{l}{ Concentration } & & \\
\cline { 3 - 5 } & & & $\mathrm{A}$ & $\mathrm{B}$ & $\mathrm{C}$ \\
\cline { 3 - 5 } & & $\mathrm{mg} / \mathrm{mL}$ & $\%$ & $\%$ \\
\hline Bicyclogermacrene & 1505 & $14.50 \pm 0.94$ & 1.62 & 1.18 & 0.39 \\
$\delta$-Amorphene & 1516 & $0.14 \pm 0.00$ & 0.02 & tr. & tr. \\
$\gamma$-Cadinene & 1518 & $0.06 \pm 0.00$ & 0.01 & tr. & tr. \\
Spathulenol & 1582 & $4.53 \pm 0.80$ & 0.51 & 0.46 & 0.10 \\
Caryophyllene oxide & 1588 & $2.86 \pm 0.84$ & 0.32 & 0.14 & 0.07 \\
Globulol & 1596 & $0.75 \pm 0.07$ & 0.08 & tr. & 0.01 \\
Viridiflorol & 1597 & $0.26 \pm 0.15$ & 0.03 & tr. & tr. \\
Humulene epoxide II & 1614 & $0.26 \pm 0.01$ & 0.03 & tr. & tr. \\
epoxy-allo-Alloaromadendren & 1645 & $0.27 \pm 0.05$ & 0.03 & tr. & tr. \\
\hline
\end{tabular}

$R I$ retention indices

A-gas chromatograph Varian GC 3800 with mass detector Varian 4000 MS/MS

B-gas chromatograph Varian GC 3800 with FID detector

C-gas chromatograph Varian GC 450 with Headspace and with mass detector Varian 320-MS

tr.-less than $0.05 \mathrm{mg} / \mathrm{mL}$ and $0.01 \%$

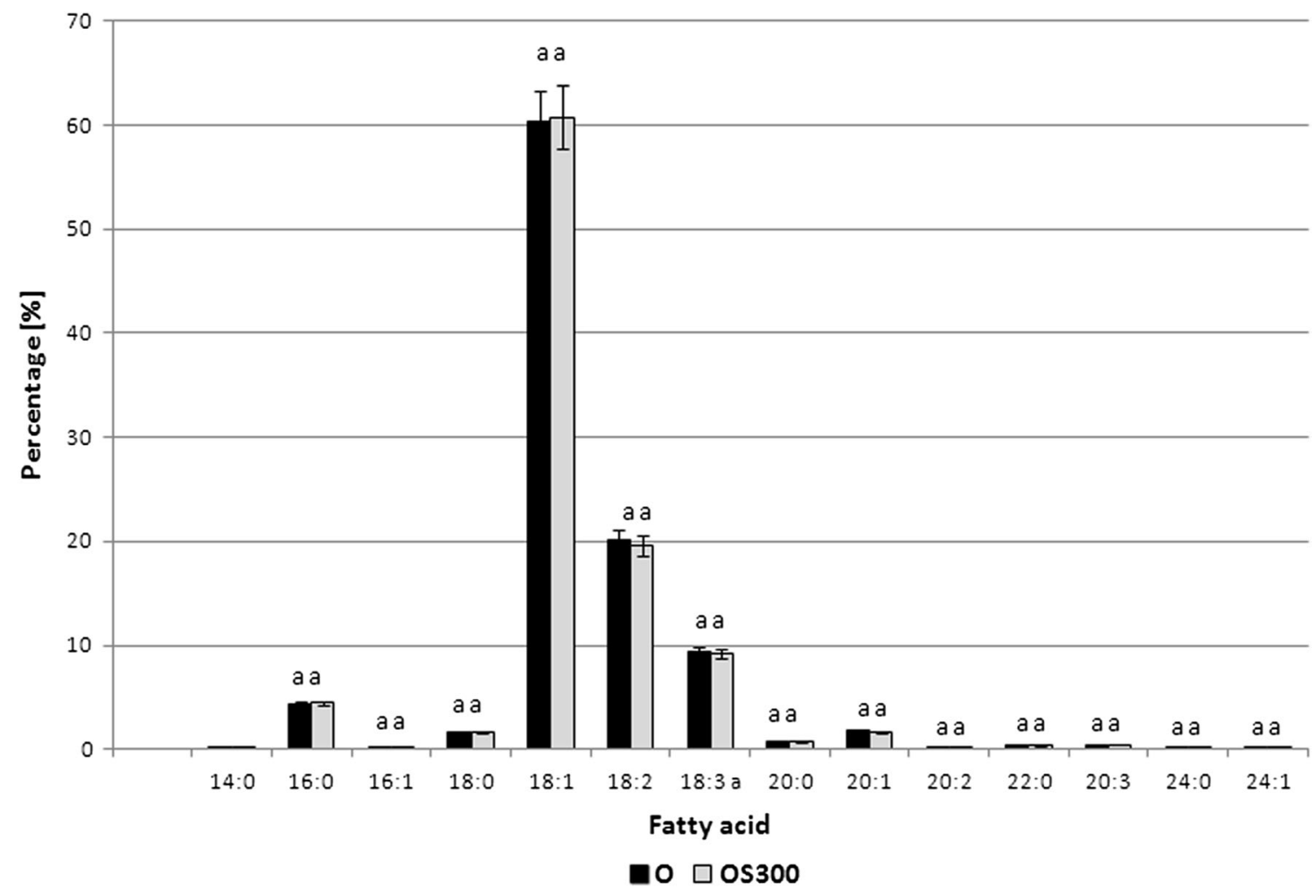

Fig. 1 Fatty acid composition of rapeseed oil Kujawski (Kowalski et al. 2018). O—rapeseed oil Kujawski, OS300—rapeseed oil Kujawski subjected to sonication for $300 \mathrm{~min}, \mathrm{a}, \mathrm{b}, \mathrm{c}, \mathrm{d}$...-values designated with the same letters do not significantly differ at 5\% error (Duncan's test)

"D", $300 \mathrm{~min}$ at $25^{\circ} \mathrm{C}$ - contained a similar level of flavours-34.18 $\mu \mathrm{g} / \mathrm{mL}$. Oils macerated for $60 \mathrm{~min}$ with classic shaking ("A") as well as with sonication (" $\mathrm{C}$ ") had lower concentrations of aromatic compounds compared to macerations conducted for 300 min ("B"and "D"). The least effective method was that of maceration with the use of microwaves- "E" at $40{ }^{\circ} \mathrm{C}-12.44 \mu \mathrm{g} / \mathrm{mL}$, however, in that oil a larger number of volatile compounds was 


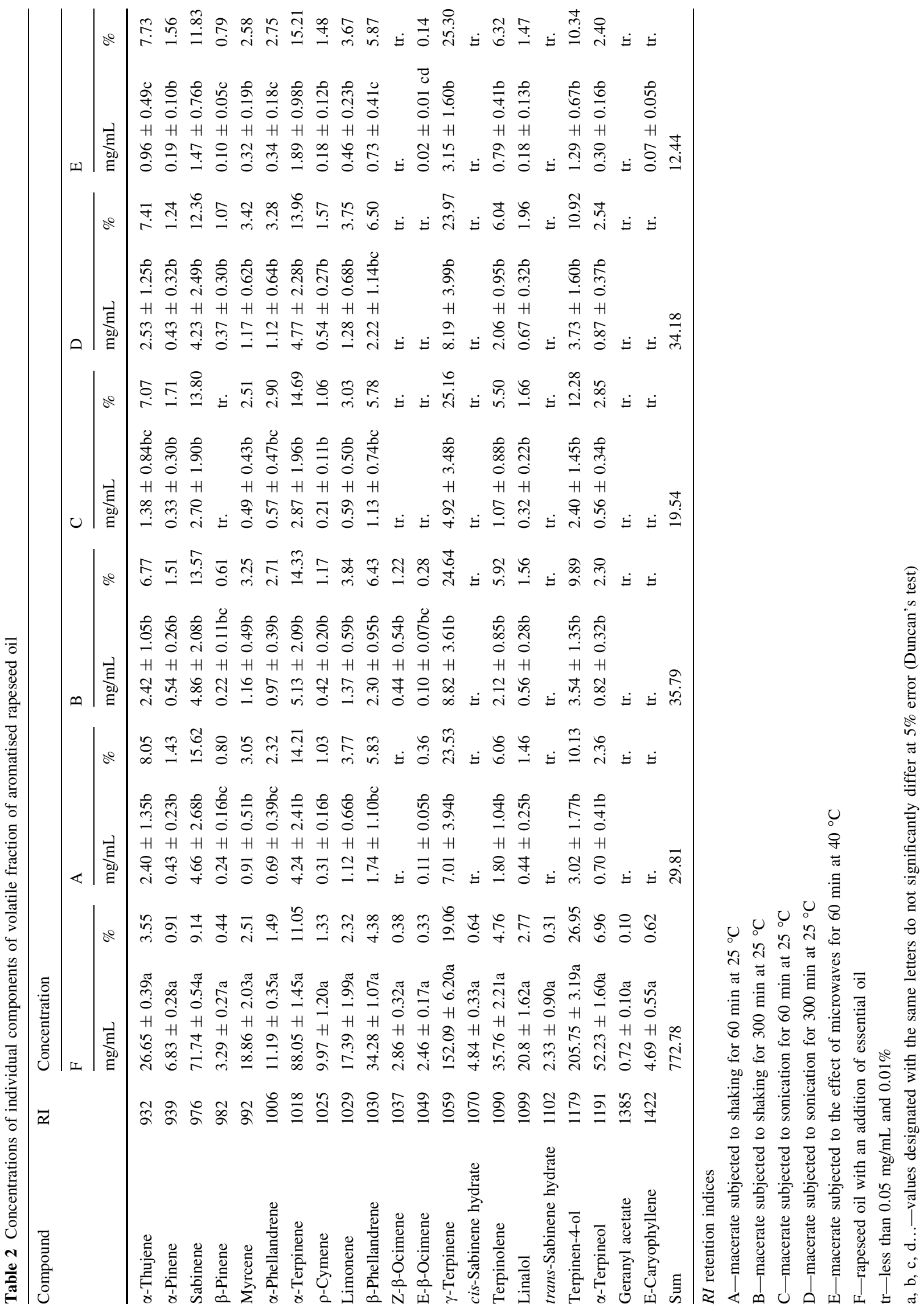




\section{Chromatogram Plots}

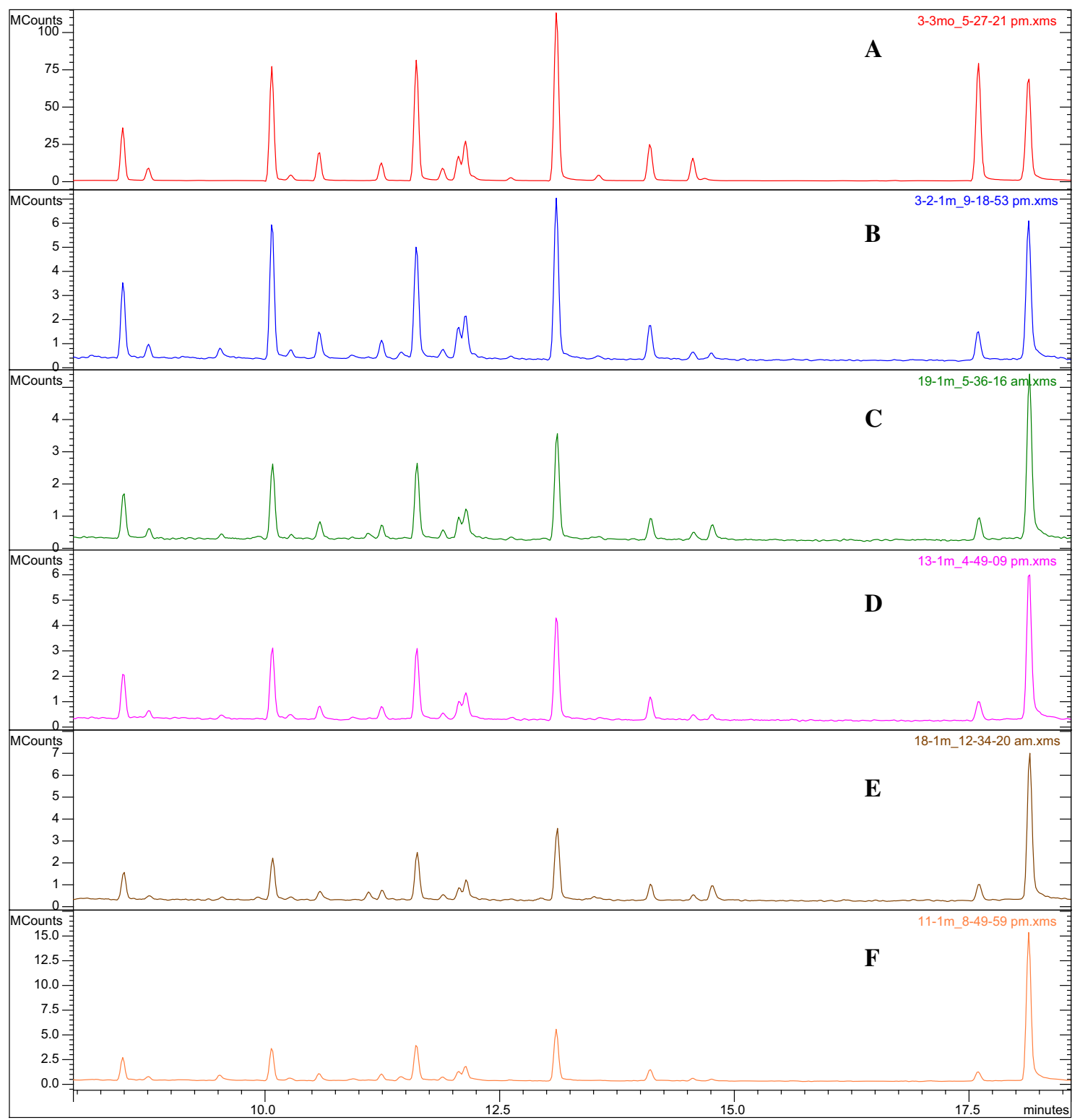

Fig. 2 Chromatograms (GC/MS) of the volatile compounds found in flavoured rapeseed oil. A-macerate subjected to shaking for $60 \mathrm{~min}$ at $25{ }^{\circ} \mathrm{C}, \mathrm{B}$-macerate subjected to shaking for $300 \mathrm{~min}$ at $25^{\circ} \mathrm{C}$, $\mathrm{C}$-macerate subjected to sonication for $60 \mathrm{~min}$ at $25^{\circ} \mathrm{C}$, D-

observed-17. It can be assumed that the temperature of $40{ }^{\circ} \mathrm{C}$ (for the other systems in the experiment the temperature was $25^{\circ} \mathrm{C}$ ) during microwave maceration resulted in losses of components of the essential oil, which was observed phenomenon when using such assisted extraction (Ibrahim et al. 2012). The total amounts of aromatic compounds liberated from rapeseed oil in the course of analysis of the above-surface phase (headspace technique) were considerably lower that the concentrations that should be observed on the basis of calculations resulting from the macerate subjected to sonication for $300 \mathrm{~min}$ at $25^{\circ} \mathrm{C}$, E-macerate subjected to the effect of microwaves for $60 \mathrm{~min}$ at $40{ }^{\circ} \mathrm{C}$, Frapeseed oil with an addition of essential oil

addition of the raw materials and the essential oil. This fact may be related with various processes. Firstly, oil is a excellent carrier for aromatic substances, at the same time slowing down the release of volatile substances to the atmosphere-therefore components of essential oils can be bound is some manner with the fat system, which may be reflected in their retention and concentration of the volatile fraction. Secondly, in the process of maceration of herb of marjoram oil as a lipophilic medium liberates mainly components similar to that medium (the extraction process 
releases mainly lipophilic components). The extraction efficiency of maceration processes can be increased through by the choosing the right solvent or through modification of process parameters, e.g. extension of the time of maceration and/or increase of solvent temperature (Bucić-Kojić et al. 2009; Efthymiopoulos et al. 2018). However, referring to the so-called percentage share of aromatic components in the particular oil macerates one can conclude that it is fairly similar (similar distribution of components, while the absolute values, i.e. concentrations, display differences), which means that volatile compounds dissolve in oil with a similar trend, irrespective of the applied techniques of maceration. Comparing the percentage shares of volatile components in the macerates with oil aromatised through an addition of essential oil, especially notable differences were observed in the case of terpinen4-ol, $\gamma$-terpinene, $\alpha$-terpinene and sabinene.

Ultrasounds can effectively increase the efficiency of the process of extraction (Assami et al. 2016). Positive influence was also observed in ultrasound augmented distillation of essential oils, resulting in enhanced extraction of aromatic substances from plant secretory structures (Kowalski et al. 2015). Kowalski and Wawrzykowski (2009), and Da Porto and Decorti (2009) demonstrated that essential oils distilled from plant material in the presence of ultrasounds differed in their chemical composition from oils extracted with the classic method. Those authors attribute the changes to probable structural transformations of unstable chemical compounds under the effect of ultrasounds due to the production of nanoparticles (Taurozzi et al. 2011). In the experiment presented here no significant quantitative differences were observed, which may be related with the stabilisation of volatile aromatic compounds in the environment of rapeseed oil.

The application of microwaves in the distillation of essential oil has significant advantages in relation to the traditional solutions, and namely: shorter time of isolation (15 min compared to $180 \mathrm{~min}$ in the case of water distillation), enhanced antibacterial effect of the oil due to the formation of larger amounts of oxygen compounds. Under the effect of microwaves changes take place in the plant material, such as damage of cells and cell walls, destruction of secretory glands when some of them are filled with oil, which significantly accelerates the process of distillation. The observed changes are related with strains caused by rapid and violent evaporation of water, which causes the cracking and destruction of cell wall (Bousbia et al. 2009). However, the results obtained for macerate are not so satisfactory, as the lowest concentration of the substance was found in the oil solution, which may be the result of the influence of microwaves on the volatility of compounds (increasing the release of fragrances from the oil matrix). It may also be a consequence of increasing temperature to $40{ }^{\circ} \mathrm{C}$ (compared to $25^{\circ} \mathrm{C}$ ).

It can be concluded that microwave maceration was characterised by the lowest efficiency, while classic maceration and maceration with sonication were characterised by relatively similar levels of efficiency. Taking into account the economic costs of the somication and microwave processes, one should consider whether such small quantitative differences may have a bearing on the final profitability of the process.

The available literature lacks reports within similar areas, therefore it is difficult to compare the results obtained with literature data.

Previously published results of the study on aromatization of oil with rosemary are generally consistent with the results presented above (Kowalski et al. 2018). Rosemary and marjoram belong to the same botanical family (lamiaceae) and are characterized by a similar anatomical structure and the occurrence of similar secretory structures. On this basis, it can be concluded that the release of aromatic substances to the oil is also similar. At this point, the question arises whether similar relationships could exist for botanically and anatomically differentiated plant materials?

\section{Antioxidant properties of the aromatised oils}

The analyzed macerates of rapeseed oil Kujawski with the marjoram herb were characterised by varied capacity for quenching DPPH radicals (Table 3 and Fig. 3). After $30 \mathrm{~min}$ the analysed macerates quenched from $26.21 \%$

Table 3 DPPH radical quenching by the analysed macerates

\begin{tabular}{lc}
\hline Sample & DPPH radical quenching (\%) \\
\hline B & $29.33 \pm 0.46 \mathrm{a}$ \\
D & $29.13 \pm 1.12 \mathrm{a}$ \\
A & $28.40 \pm 1.27 \mathrm{ab}$ \\
E & $27.57 \pm 1.73 \mathrm{abc}$ \\
C & $26.21 \pm 1.65 \mathrm{bcd}$ \\
F & $25.21 \pm 1.50 \mathrm{~cd}$ \\
$\mathrm{~K}$ & $24.50 \pm 0.52 \mathrm{~d}$ \\
\hline A-macerate subjected to shaking for 60 min at $25{ }^{\circ} \mathrm{C}$ \\
B-macerate subjected to shaking for 300 min at $25{ }^{\circ} \mathrm{C}$ \\
C-macerate subjected to sonication for 60 min at $25{ }^{\circ} \mathrm{C}$ \\
D-macerate subjected to sonication for 300 min at $25{ }^{\circ} \mathrm{C}$ \\
E-macerate subjected to the effect of microwaves for 60 min at \\
$40{ }^{\circ} \mathrm{C}$ \\
F-rapeseed oil with an addition of essential oil \\
K-control, rapeseed oil \\
a, b, c, d...-values designated with the same letters do not signifi- \\
cantly differ at $5 \%$ error (Duncan's test)
\end{tabular}




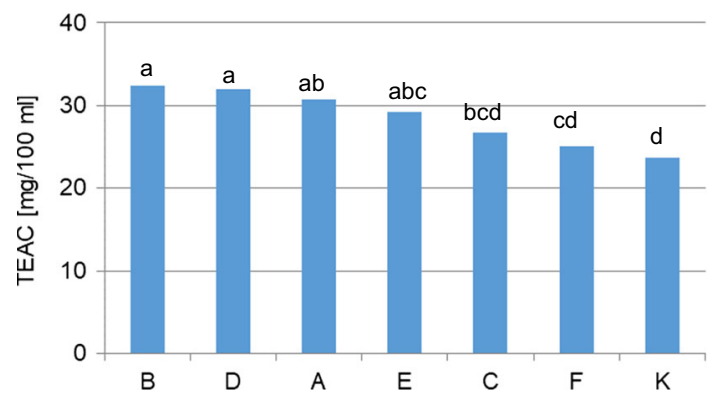

Fig. 3 Antiradical activity of the macerates towards DPPH radicals expressed in Trolox equivalents (TEAC, Trolox Equivalent Antioxidant Capacity). A-macerate subjected to shaking for $60 \mathrm{~min}$ at $25{ }^{\circ} \mathrm{C}, \mathrm{B}-$ macerate subjected to shaking for $300 \mathrm{~min}$ at $25^{\circ} \mathrm{C}, \mathrm{C}-$ macerate subjected to sonication for $60 \mathrm{~min}$ at $25^{\circ} \mathrm{C}$, D-macerate subjected to sonication for $300 \mathrm{~min}$ at $25^{\circ} \mathrm{C}$, E-macerate subjected to the effect of microwaves for $60 \mathrm{~min}$ at $40{ }^{\circ} \mathrm{C}, \mathrm{F}$-rapeseed oil with an addition of essential oil, $\mathrm{K}-\mathrm{control}$, rapeseed oil, $\mathrm{a}, \mathrm{b}, \mathrm{c}$, d...-values designated with the same letters do not significantly differ at $5 \%$ error (Duncan's test)

("C") to $29.33 \%$ ("B") DPPH. Macerates obtained by shaking were characterised by stronger antioxidant properties than macerates subjected top sonication, deactivating from $28.40 \%$ ("A", maceration for $60 \mathrm{~min}$ ) to $29.33 \%$ ("B", maceration for $300 \mathrm{~min}$ ) of the initial amount of DPPH radical (with sonication-26.21\%—“C" after 60 min and 29.13\% — "D" after 300 min, respectively). In the case of macerates subjected to sonication the capacity for radical neutralisation was at the level of $27.57 \%$ ("E"). The lowest capacity for quenching DPPH radical was characteristic of the sample prepared by direct addition of marjoram oil to rapeseed oil- "F" (25.21\%). In the study 6 different variants were analysed. The difference between the macerate with the highest capacity for DPPH deactivation, compared with the material that reduced the radical to the least degree, was $4.12 \%$. Converted to TEAC [mg/ $100 \mathrm{~mL}$, the results can be arranged in a sequence in terms of antioxidant activity as follows (Fig. 1): macerate 300 min., shaking $(32.36 \pm 0.82), 300 \mathrm{~min}$., sonication (32.01 \pm 2.01$)$, 60 min., shaking (30.70 \pm 2.03$)$, 60 min., microwaves $\quad(29.21 \pm 3.09), \quad 60 \mathrm{~min}$., sonication $(26.76 \pm 2.96)$, direct addition of essential oil to oil $(24.99 \pm 2.69)$.

Oxidation of lipids is a complex process that can be generated in three different ways: (1) with the participation of free radicals on the pathway of non-enzymatic chain reactions, (2) on the pathway of photo-oxidation (non-enzymatic, with no participation of free radicals), (3) on the pathway of enzymatic reactions (Miguel 2010). Among factors that can slow down the reaction of oxidation one can include reduced temperature, reduced oxygen pressure, inert gas environment, and also the presence of antioxidants (Kamal-Eldin and Pokorný 2005). An interesting group of compounds with antioxidant properties are essential oils (Miguel 2010), among which marjoram oil can have an application as an additive stabilising the composition of edible fats (Ezzeddine Nejla and Moncef 2006). The best known components of essential oils with antioxidant properties are phenolic compounds (thymol, carvacrol), however, the oils contain chemically diversified components, and some of them can even have a pro-oxidant effect (Amorati et al. 2013). Obviously, when analysing those natural mixtures, one should take into account their complex composition and the synergistic effect of the entire complex of chemical compounds (Amorati et al. 2013). Earlier research (Miguel 2010) indicates that volatile components with documented antioxidant activity include: $\alpha$-terpineol, terpinen-4-ol, $\gamma$-terpinene, $\alpha$-terpinene, $\alpha$-thujene and sabinene, the presence of which was confirmed in marjoram-aromatised oils in the present study. In spite of the highest concentration of volatile compounds in the sample aromatised by direct addition of essential oil, that variant was characterised by the lowest antioxidant activity. Apart from essential oil, the herb of marjoram contains also other active components, i.e. diterpenes (carnosic acid, carnosol), triterpenes (ursolic acid and oleanolic acid), sterols, ether derivatives (monomethyl hydroquinone ether, arbutins), flavonoids (apigenins, hispidulins, luteolin-7-O-beta-glucoside, 6-hydroxyapigenin, $7-\mathrm{O}-\beta$-glucosides), that migrate to the solution during maceration (Vagi et al. 2005; Fecka and Turek 2008). Probably, it is the components mentioned above, occurring in marjoram and not the essential oil as such, that are responsible for the higher capacity for quenching DPPH radicals in macerates compared to the sample prepared through the addition of marjoram oil to rapeseed oil. Clodoveo et al. (2016) observed higher concentrations of polyphenol compounds and increased antiradical activity in aromatised olive oil by the use of ultrasound. In contrast, in our work, ultrasounds did not increase antiradical activity compared to classical maceration. Paduano et al. (2014) showed that the ultrasoundassisted extraction of capsaicinoids from chili peppers (Capsicum annuum L.) into flavored olive oil did not increase the antioxidant properties of the product compared to classical extraction, while the use of microwave-assisted extraction made it possible to obtain extracts of significantly higher antioxidant activity compared to the control sample. A significant antioxidant activity compared to the control sample was displayed by the macerate subjected to the effect of microwaves $(29.21$ TEAC $[\mathrm{mg} / 100 \mathrm{~mL})$, at relatively low volatile substance content $-12.44 \mathrm{mg} / \mathrm{mL}$. This can be attributed to the degradation of cell structures and liberation of phenolic compounds under the effect of microwaves (Bousbia et al. 2009).

In addition, analysis of the control sample $\mathrm{K}$ revealed that pure rapeseed oil is also characterised by DPPH radical 
quenching capacity at the level of $24.50 \%$ (23.70 TEAC $[\mathrm{mg} / 100 \mathrm{~mL}]$ ), and the addition of herb improves that capacity only slightly. Seeds of oil-bearing plants contain such compounds as fatty acids, phenolics, tocopherols, sterols, stanols, phospholipids, waxes, squalene and other hydrocarbons that migrate to oils during the process of cold pressing, due to which they can prevent oxidation caused free radicals (Yu et al. 2002). Canolol, present in rapeseed oil, being the product of decarboxylation of sinapinic acid, has strong antioxidant properties (Koski et al. 2002). The study of antioxidant activity of rapeseed oil conducted by Sigier et al. (2008) demonstrated reduction of DPPH radical at the level of $50 \%$. Values of DPPH radical reduction obtained in this experiment, lower by half $(24.50 \%)$, can be attributed to varietal, natural and technological factors that may affect the final chemical composition of oils. Antioxidant activity of the analysed samples is relatively low (ca. 28\% depending on the method of maceration) compared to literature data, e.g. for fruit tea extracts-ca. $64 \%$ of quenched DPPH radicals after 10 min (Szlachta and Małecka 2008), while the antioxidant activity of the experimental aromatised oils is higher than the activity of such dry spices as pepper, parsley tops or caraway (ca.18\%) (Gawlik-Dziki and Świeca 2007). Whereas the DPPH radical scavenging activity of oils aromatised with rosemary under similar experimental conditions was higher, reaching the following maximum values: $30.31 \%$ (sonication for $60 \mathrm{~min}$ at $25^{\circ} \mathrm{C}$ ) and $31.89 \%$ (sonication for $300 \mathrm{~min}$ at $25^{\circ} \mathrm{C}$ ) (Kowalski et al. 2018). Differences between aromatised oils obtained in parallel experiments, differing in addition to the vegetable raw material, probably result from their chemical characteristics. Chiang Chan et al. (2012) showed that fresh rosemary herb was characterized by a higher antioxidant activity compared to marjoram herb, which is confirmed by the results of the presented work and the results published earlier (Kowalski et al. 2018).

Studies show that the fat aromatization method affects the content of volatile compounds, the concentration of which in turn does not necessarily involve an increase in antioxidant properties. The simplest and most effective way of oil aromatization is a direct addition of essential oil, however our study showed that the obtained product did not have the highest antioxidant activity. Whereas classical methods of aromatization (maceration) or alternative methods with ultrasonic or microwave support may lead to a product with better antioxidant properties. Another aspect that requires further comprehensive research is chemical and morphological diversity of plant materials.

\section{Conclusion}

1. The study showed that the method of aromatisation affects the content of volatile substances.

2. It was demonstrated that direct addition of essential oil to oil is the most effective method of aromatisation in terms of the content of volatile components.

3. It was demonstrated that the time of extraction and sonication affect the efficiency of the process of aromatisation.

4. It was found that the antioxidant activity of aromatised oils did not depend on the concentration of volatile compounds in the oil.

5. It was demonstrated that oils aromatised through maceration of plant material with oil were characterised by higher antioxidant activity, which was most likely related with the presence of active substances other than volatile compounds.

\section{Compliance with ethical standards}

Conflict of interest All authors declare that they have no conflicts of interest.

Human and animal rights This article does not contain any studies with human participants or animals performed by any of the authors.

Open Access This article is distributed under the terms of the Creative Commons Attribution 4.0 International License (http://crea tivecommons.org/licenses/by/4.0/), which permits unrestricted use, distribution, and reproduction in any medium, provided you give appropriate credit to the original author(s) and the source, provide a link to the Creative Commons license, and indicate if changes were made.

\section{References}

Amorati R, Foti MC, Valgimigli L (2013) Antioxidant activity of essential oils. J Agric Food Chem 61(46):10835-10847. https:// doi.org/10.1021/jf403496k

Assami K, Chemat S, Meklati BY, Chemat F (2016) Ultrasoundassisted aromatisation with condiments as an enabling technique for olive oil flavouring and shelf life enhancement. Food Anal Method 9:982-990. https://doi.org/10.1007/s12161-015-0273-9

Ayadi MA, Grati Kamoun N, Attia H (2009) Physico-chemical change and heat stability of extra virgin olive oils flavoured by selected Tunisian aromatic plants. Food Chem Toxicol 47(10):2613-2619. https://doi.org/10.1007/s12161-015-0273-9

Bauer K, Garbe D, Surburg H (1990) Common fragrance and flavor materials. VCH Verlagsgesellschaft $\mathrm{mbH}$, Weinheim

Bousbia N, Vian MA, Ferhat MA, Petitcolas E, Meklati BY, Chemat F (2009) Comparison of two isolation methods for essential oil from rosemary leaves: hydrodistillation and microwave hydrodiffusion and gravity. Food Chem 114:355-362. https://doi.org/ 10.1016/j.foodchem.2008.09.106

Brud W (2000) Biological activity of essential oils used in food flavourings. Przem Spoż 54(4):14-15 
Bruni R, Medici A, Andreotti E, Fantin C, Muzzoli M, Dehesa M, Romagnoli C, Sacchetti G (2004) Chemical composition and biological activities of Ishpingo essential oil, a traditional Ecuadorian spice from Ocotea quixos (Lam.) Kosterm. (Lauraceae) flower calices. Food Chem 85:415-421. https://doi.org/ 10.1016/j.foodchem.2003.07.019

Bucić-Kojić A, Planinić M, Srećko T, Jakobek M, Šeruga L (2009) Influence of solvent and temperature on extraction of phenolic compounds from grape seed, antioxidant activity and colour of extract. Int J Food Sci Technol 44:2394-2401. https://doi.org/10. 1111/j.1365-2621.2008.01876.x

Chiang Chan EW, Kong LQ, Yee KY, Chua WY, Loo TY (2012) Antioxidant and antibacterial properties of some fresh and dried Labiatae herbs. Free Rad Antioxid 2(3):20-27. https://doi.org/ 10.5530/ax.2012.3.3

Clodoveo ML, Dipalmo T, Crupi P, Durante V, Pesce V, Maiellaro I, Lovece A, Mercurio A, Laghezza A, Corbo F, Franchini C (2016) Comparison between different flavored olive oil production techniques: healthy value and process efficiency. Plant Foods Hum Nutr 71:81-87. https://doi.org/10.1007/s11130-0160528-7

Da Porto C, Decorti D (2009) Ultrasound-assisted extraction coupled with under vacuum distillation of flavour compounds from spearmint (carvone-rich) plants: comparison with conventional hydrodistillation. Ultrason Sonochem 16:795-799. https://doi. org/10.1016/j.ultsonch.2009.03.010

Efthymiopoulos I, Hellier P, Ladommatos N, Russo-Profili A, Eveleigh A, Aliev A, Kay A, Mills-Lamptey B (2018) Influence of solvent selection and extraction temperature on yield and composition of lipids extracted from spent coffee grounds. Ind Crops Prod 119:49-56. https://doi.org/10.1016/j.indcrop.2018. 04.008

Ezzeddine Nejla BH-B, Moncef CM (2006) Antioxidant activity of oil from Tunisia. J Essent Oil Bear Plants 9(1):88-92. https://doi. org/10.1080/0972060X.2006.10643477

Fecka I, Turek S (2008) Determination of polyphenolic compounds in commercial herbal drugs and spices from Lamiaceae: thyme, wild thyme and sweet marjoram by chromatographic techniques. Food Chem 108:1039-1053. https://doi.org/10.1016/j.foodchem. 2007.11.035

Gawlik-Dziki U, Świeca M (2007) Influence of simulated digestion in various $\mathrm{pH}$ conditions on antioxidant activity and composition of extracts from selected spices. Herba Pol 3(53):279-285

Ibrahim GE, El-Ghorab AH, El-Massry KF, Osman F (2012) Effect of microwave heating on flavour generation and food processing. In: Cao W (Ed.), The development and application of microwave heating (pp 17-44). Intech Open Science. http://dx.doi.org/10. 5772/49935

Kamal-Eldin A, Pokorný J (2005) Analysis of lipid oxidation. AOCS Press, Champaign

Koski A, Psomiadou E, Tsimidou M, Hopia A, Kefalas P, Wahala K, Heinonen M (2002) Oxidative stability and minor constituents of virgin olive oil and cold-pressed rapeseed oil. Eur Food Res Technol 214:294-298. https://doi.org/10.1007/s00217-0010479-5

Kowalski R (2007) GC analysis of changes in the fatty acid composition in sunflower and olive oils heated with quercetin, caffeic acid and protocatechuic acid, and butylated hydroxyanisole. Acta Chromatogr 18:15-23

Kowalski R (2009) Silphium L. extracts-composition and protective effect on fatty acids content in sunflower oil subjected to heating and storage. Food Chem 112:820-830. https://doi.org/10.1016/j. foodchem.2008.06.038

Kowalski R, Wawrzykowski J (2009) Effect of ultrasound-assisted maceration on the quality of oil form the leaves of Thymus vulgaris L. Flav Fragr J 24:69-74. https://doi.org/10.1002/ffj. 1918

Kowalski R, Kowalska G, Jamroz J, Nawrocka A, Metyk D (2015) Effect of the ultrasound-assisted preliminary maceration on the efficiency of the essential oil distillation from selected herbal raw materials. Ultrason Sonochem 24:214-220. https://doi.org/ 10.1016/j.ultsonch.2014.12.008

Kowalski R, Kowalska G, Pankiewicz U, Mazurek A, Sujka M, Włodarczyk-Stasiak M, Kałwa K (2018) Effect of the method of rapeseed oil aromatisation with rosemary Rosmarinus officinalis L. on the content of volatile fraction. LWT Food Sci Technol 95:40-46. https://doi.org/10.1016/j.lwt.2018.04.045

Lis A, Piter S, Góra J (2007) A comparative study on the content and chemical composition of essential oils in commercial aromatic seasonings. Herba Pol 1(53):21-26

Miguel MG (2010) Antioxidant and anti-inflammatory activities of essential oil: a short revision. Molecules 15:9252-9287. https:// doi.org/10.3390/molecules 15129252

Paduano A, Caporaso N, Santini A, Sacchi R (2014) Microwave and ultrasound-assisted extraction of capsaicinoids from chili peppers (Capsicum annuum L.) in flavored olive oil. J Food Res 3(4):51-59. https://doi.org/10.5539/jfr.v3n4p51

Sánchez-Moreno C, Larrauri JA, Saura-Calixto FD (1998) A procedure to measure the antiradical efficiency of polyphenols. J Sci Food Agr 76:270-276. https://doi.org/10.1002/(SICI)10970010(199802)76:2\%3c270:AID-JSFA945\%3e3.0.CO;2-9

Sigier A, Nogala-Kałucka M, Lampart-Szczapa E, Hoffman A (2005) Antioxidant activity of phenolic compounds of selected coldpressed and refined plant oils. Oilseed Crops 2(26):548-559

Sigier A, Nogala-Kalucka M, Lampart-Szczapa E (2008) The content and antioxidant activity of phenolic compounds in cold-pressed plant oils. J Food Lipids 15:137-149

Srinivasan K (2005) Role of spices beyond food flavouring: nutraceuticals with multiple health effects. Food Rev Int 21:167-188. https://doi.org/10.1081/FRI-200051872

Szlachta M, Małecka M (2008) Antioxidant properties of fruit teas. Food Sci Technol Quality 1(56):92-102

Taurozzi JS, Hackley VA, Wiesner MR (2011) Ultrasonic dispersion of nanoparticles for environmental, health and safety assessment-issues and recommendations. Nanotoxicology 5(4):711-729. https://doi.org/10.3109/17435390.2010.528846

Tournier C, Sulmont-Rossé C, Guichard E (2007) Flavour perception: aroma, taste and texture interactions. Food 1(2):246-257

Turek C, Stintzing FC (2013) Stability of essential oils: a review. Compr Rev Food Sci Food Saf 12(1):40-53. https://doi.org/10. 1111/1541-4337.12006

Vagi E, Rapav E, Hadolin M, Vásárhelyiné P, Balazs A, Blazovics A (2005) Phenolic and triterpenoid antioxidants from Origanum majorana L. herb and extracts obtained with different solvents. J Agr Food Chem 1(53):17-21. https://doi.org/10.1021/ jf048777p

Yu L, Haley S, Perret J, Harris M, Wilson J, Qian M (2002) Free radical scavenging properties of wheat extracts. J Agr Food Chem 50:1619-1624. https://doi.org/10.1021/jf010964p

Publisher's Note Springer Nature remains neutral with regard to jurisdictional claims in published maps and institutional affiliations. 